\title{
Impact of Organizational Communication Strength on Employee Engagement: The Mediating Role of Perceived Supervisor Support and Moderating Role of Organizational Trust
}

\author{
DR. MUZAMMEL SHAH \\ Assistant Professor, Air University School of Management (AUSOM). \\ Air University, Islamabad. \\ Muzammel.shah@mail.au.edu.pk \\ BAHRAWAR SAID \\ Ph.D. Scholar at University of Malakand \\ Dir Lower, Pakistan. \\ bahrawar.szabist@gmail.com \\ SORATH MAHAR \\ PhD Scholar, Institute of Business Studies and Leadership \\ Abdul Wali Khan University, Mardan \\ sorathm@yahoo.com
}

\begin{abstract}
Companies need employees who are passionate about their job and strive to take organization to height of glory.Owing to high competition in banking sector, it is pertinent to note that banks need to differentiate themselves from competitors. The objective of this study was to examine the relationship of organizational communication strength and employee engagement, with mediating effect of perceived supervisor support and moderating role of organizational trust. Data was collected from a sample 244 employees of banking sector who were through simple random sampling. Cronbach's alpha was used to test the reliability of the scales used in the study. Correlation and regression analyses were used to analyze the hypothesized relationships. The findings revealed a significant positive relationship between communication strengthand employee's engagement. Perceived supervisor support mediated the relationship ofcommunication strength and employee's engagement. Organizational trust moderated the relationship of Perceived supervisor support and employee's engagement. Organizations should focus on promoting a strong communication system to increase the dedication, vigor and absorption of employees.
\end{abstract}

Key words: Communication, trust, engagement, reliability, correlation, regression

\section{Introduction}

Employee engagement has remained the topic of discussion of numerous reports because of the contribution of engaged employees to the success of organizations. In today's dynamic and competitive environment, organizations achieve sustained competitive advantage via committed and engaged workforce (Wollard \& Shuck, 2011).Engagement is the psychological state in which employees are completely present and immersed in their work (May et al., 2004). Engaged employees are more 
likely to volunteer their time and services for the company beyond the call of their job descriptions. It is directly associated with organizationalsuccess. The reason why employee engagement is so important to companies is that there are a host of benefits associated with high employee engagement. Abusiness with 'high' employee engagement islikely to outclass those with 'low' employee engagement. Freeny and Tiernan, (2006) highlighted the value of engagement not only as a state of well-being but also as a predictor of high performance.Engaged employees behave in a positive and cooperative way. They work for their own benefit as well as organizational benefit (Alfes et al, 2010). They take great interest in their work, outperform others in their duties and commitment and go an extra mile in the struggle for the success of organization. They see their work more meaningful and fulfilling and have increased job satisfaction. Employee engagement affect work related attitudes (Bakker \& Xanthopoulou, 2009; Balain \& Sparrow, 2009).

Research has also supported that the key driver of engagement is communication. Organizations that effectively communicate with employee experienced high level of engagement. Abugre, (2013) suggested that organization makes successes if managers and employees have strong interpersonal communication free from centralized organizational culture. Moreover,Rees, Alfes and Getenby, (2013) found evidences that strong communication within organization builds employees trust with line managers and senior managers, which ultimately lead to increased employee engagement within organization. Similarly, Townsend, Wilkinson and Burgess (2014) asserted that strong communication among employees and leaders improve employment relations and as a result gives strength to employment engagement. Supervisor support is the key towards employee engagement in a business enterprise. Supervisors support increases job satisfaction, employee commitment level, retention and employee engagement in organizations, (Shuck and Wollard, 2011). Furthermore, organizational trust played an elaborating role in various variables which were instrumental in exploring the employee's engagement and perceived supervisor support.

Many studies (Abubakar, Dilbeck \&McCroskey, 2010; Rees, Alfes \& Getenby, 2013;Townsend, Wilkinson \& Burgess, 2014) uncovered the relationship of organizational communication and employee engagement. However, scant research exist that study the mediating role of perceived supervisor support and moderating influence of employee trust on the relationship of organizational communication and employee engagement. Thus, it was imperative to study the mediating influence of perceived supervisor support and moderating role of employee trust on the association of organizational communication and employee engagement. The study will provide an understanding of organizational atmosphere where employees demonstrate more energy and dedication during workdays.

\section{Literature Review}

\subsection{1 Employee Engagement}

Kahn (1990) was the first who added the term employee engagement into the academic world of business. It referred to the physical, cognitive and emotional attachment of organizational mem-bers to their work roles (Kahn, 1990). Schaufeli et al., (2002) defined Work engagement as a constructive, satisfying, professional state of mind that is characterized by interest, energy and devotion. According to Bakker and Salanova (2006) engagement is a multi-dimensional construct consists of vigor, dedication and absorption, for all these creates an internal state of engagement. Macey and Schneider (2008) as pro-social activities of employees that lead to benefit 
of employees and organization both. Nohria et al., (2008) referred to employee engagement as the effort, energy and initiative that employees bring to their jobs, which can be easily differentiated from employee's job satisfaction and organizational commitment. Employee engagement reflects an emotional attachment and psychological ties to one's work in conjunction with commitment to the job and a consequent willingness to go beyond the call of duty. Dvir et al., (2002) stated that engagement in organizational context has dimensions such as activity, initiative and responsibility on the part of the dedicated employees, who are committed to use their energies and potentials for the best interest and success of their organizations (Macey \& Schneider, 2008).

Several researchers (Maslach \& Leiter, 1997; Bhatnagar \&Biswas, 2010;Shuck \& Wollard, 2011;Saks, 2011;Rurkkum \& Bartlett, 2012;Sibiya et al., 2014) have studied employee engagement with burnout, workplace spirituality, job satisfaction, employee performance, and organizational citizenship behavior and turnover intention. Torrente et al, (2012) confirmed the mediating role of team work engagement on the relationshipof organizational trust and engagement level with organization. Diedricks and Rothman, (2012) analyzed the employee work engagement as a mediator between the work role fit and availability of personal resources. Alfes et al,. (2013) found that employee engagement mediated between HRM practices and behavioral outcomes of employees. Penger and Cerne, (2014) found a significant relationship between authentic leadership, job satisfaction and work engagement.

\subsection{2 Organizational Communication Strength}

Communication is all about the ability to speak and listen. Communication is a two way process of transferring ideas feelings and the like to the desired target audience. It may not always be a two way process (Berger, 2008); it is rather the exchange of ideas and flow of information from the sender to the receiver through some medium. According to Shamir, Berger (2008) stated that internal communication is a central process in which employees create relationships, make meanings, share information and construct organizational culture. Communication and development are interlinked and interdependent. No concept of development can be converted into reality without employing the process and techniques of communication (Nohria et al., 2008). Abubakar, Dilbeckand McCroskey (2010) found that communication partially mediated the relationship between LXM and employee engagement in an organization. Payne (2014) analyzed that organization dissent among supervisors and employees can be a constructive and valuable form of communication and is influenced by a variety of communication factors. It means communication strength is also responsible for conflicts among supervisors and as well as employees in organizations.

Several other researchers (Neves and Eisenberger, 2012 ; Decramer et al., 2013;Snell, Yi \& Chak, 2013) have assessed the role of organizational communication in elaborating the role of various variables such as perceived organization support, employee's performance, job satisfaction and employee engagement. According to Alfes et al., (2013) relationship of behavioral outcomes and employee engagement is moderated by perceived organizational support for employees by supervisors and leader-member exchange of communication.

\subsection{3 Perceived Supervisor Support}

Perceived supervisors support is defined as how employees perceive and feel that their contribution in organizational success is favored and appreciated by supervisors 
and how much their concerns and well-being is taken into account. Evidence suggested that supervisor support can lessen the severity of social and job related conflicts that employees experienced and the after effects of such conflicts. Supervisor support thus acted as a buffer between job stress and burnout and family/work related conflicts, which were faced by employees in different stages of job tenure in an organization.Supervisor support is considered the key towards employee engagement in a business enterprise. It was related to the help that supervisors gave to the middle and lower level employees while conducting their day to day tasks in organizations (Westbrook, 2015). Supervisor support can be regarded as instrumental in employee engagement. Supervisory support increased job satisfaction, employee commitment level, retention and engagement in organizations (Wollard \& Shuck, 2011). Research has shown that employees who had supportive and caring supervisors experiencedincreased job satisfaction, greater job commitment, increased loyalty and a better balance between work and family life (Avolio et al, 2004). This tendency ultimately leads to greater work engagement by employees and thus they use full potentials for goals attainment in organizations.

Many scholars have reported the significant relationship of perceived supervisor support with other important outcomes such as organizational commitment, turnover intention, organizational citizenship behavior and employee's engagement (Liu \& Ding, 2012; McCarthy et al., 2013;Snell, Yi \& Chak, 2013; Wang, 2014). According to Mills, Mathews, Henning and Woo (2014) employee's supportive supervisors and supportive organizations influence employee's behavior, subordinate self-efficacy, and employee's affective commitment to the organization. Westbrook (2015) examined that perceived supervisor support has direct impact on employee performance and job engagement.

\subsection{2 .4 Organizational Trust}

Goh and Low(2014) defined trust as a psychological state comprised of intentions to accept susceptibility based on positive prospects of the actions of others. It is a much needed ingredient for employee's well-being. It promotes good working relationships and cooperation among them. Mayer et al., (1995) proposed the integrative model of organizational trust. It takes into account a person's dispositional propensity to trust. Trust is related to trustworthiness and is a function of the trustor. It is also a perception of the trustee's and is related to integrity and benevolence of the person on with trust is made. Moye and Henkin (2006) found a strong association between employee engagement and interpersonal trust in managers. Sharlie (2009) observed found strong evidences that leadership trust is linked with encouraging employees for extra role behaviors. Several other scholars (Acosta, Salanova \& Llorens, 2012:Mohamed, Kader \&Anisa, 2012; Johnson \& Shelton, 2012; Goh \& Jie, 2014;Rajablou, Sepasi \& Nourbakhsh, 2014; Top, Akdere \&Tarean, 2015) confirmed the significant relationship of organizational trust with employee engagement, job satisfaction organizational commitment, servant leadership, organizational communication, workforce spirituality, employee engagement and job performance.

\section{$5.5 \quad 2.5$ Research Hypotheses}

H1: There is positive impact of communication strength on employee engagement.

H2: There is positive impact of communication strength on perceived supervisor support.

H3: Perceived supervisor support positively impact employee engagement.

H4: Perceived supervisor support mediate the relationship between communication strength and employee engagements. 
H5: Organizational trust moderates the relationship between perceived supervisors support and employee engagement.

\section{Research Methodology}

Statistical Package for Social Sciences (SPSS) was used for data analysis. Regression and correlation analyses were used to measure the magnitude and strength of relationships among variables. Baron and Kenny (1986)tests of mediation and moderation have been used to test the hypothesized relationships.

\subsection{1 Population}

Banking sector of Pakistan has been chosen as the population of the current study. After the market de-regulation policy of the government in 2001, foreign investments were encouraged to operate in the banking sector of Pakistan. Previously the banking industry was dominated by state owned banks, which were reaping the benefits of such a huge consumer market. After de-regulation, quite many foreign as well local investors jumped into the banking sector of Pakistan, which are not only instrumental to give huge taxes to national exchequer, but also gave huge number of jobs to the people of Pakistan, especially youth. However, the banking industry was prone to various human resource related problems such as increase turnoverof employees, lower employee engagement, decreased employee commitment and burn-outs (Abbasi \& Alvi, 2012; Hasan, Akram \& Naz, 2012; Hunjra et al, 2010).

\subsection{Data Collection and Sampling Procedure}

Unit of analysis in this study was the individual(s) (employees) working in the banking sector of Pakistan.Non probability convenience sampling techniques have been used to get data through adapted questionnaire(s) for the findings of results.The study was non-contrived and cross sectional. Data was collected through a questionnaire from the employees of the different banks in Islamabad and Rawalpindi. The researcher personally visited the offices of the banks and collected data by filling questionnaires from employees. A total of 300 questionnaires were distributed among employees of banks operating in the twin cities in which 254 respondents gave their responses. Thus, the response rate was $84.66 \%$.Only 244 questionnaires were used in the study.

\subsection{Instruments}

Communication Strengthwas measured on a scale developed by Hassan and Mustafa (2013). To measureEmployee's Engagement,the scale developed by Schaufeli et al., (2002) was utilized. Perceived Supervisor Support was measured on an instrument developed by Eisenberger and Huntington(1986) while Organizational trust was measured on a scale developed by Cummings and Bromiley(1996).

\subsection{Operational definitions of variables 3.5.1 Organizational Communication}

A two way process of transferring ideas, feelings and concerns to other people with a view to enhance relationships, mutual trust, cooperation and remove confusion and misunderstanding in organization. (Shamir \& Arthur, 1993; Berger, 2008)

\subsubsection{Perceived Supervisor Support}

The perception that help and backup is available to employees from managers and supervisors in solving various organizational issues and problems related to assigned tasks. It is also related to the perception that supervisors take care of the needs and aspirations of employees in organization. (Hammer et al., 2007; Shuck \& Wollard, 2011; Westbrook, 2015) 


\subsubsection{Organizational Trust}

Willingness of an individual or group of people to expose to the actions of other people or group with a view that the later will take action or conduct certain measures without hammering the expectations of the former, without keeping eye on the later. (Mayer et al., 1995; Rousseau, Sitkin, Burt \& Camerer, 1998)

\subsubsection{Employee Engagement}

Emotional, psychological and cognitive ties of an employee with his or her organization in conjunction with full commitment to the job and willingness to go an extra mile for the success of an organization is called employee's commitment. (Alfes et al., 2002; Schaufeli et al., 2002; Macey and Schneider, 2008)

\section{Results}

\subsection{Demographic Features of the Participants}

The demographic features of the participants are presented in Table 1.

Table 1: Demographic Features of the Participants

\begin{tabular}{lcc}
\hline Demographics & Frequency & Percent \\
\hline Age & 77 & 30.3 \\
Below 25 years & 167 & 69.7 \\
25-40 years & & \\
Gender & 189 & 74.4 \\
Male & 55 & 25.6 \\
Female & 119 & 50.8 \\
Marital Status & 125 & 49.2 \\
Single & & \\
$\quad$ Married & 118 & 50.8 \\
Experience & 92 & 36.2 \\
Less than 5 years & 33 & 13.0 \\
5-10 years &
\end{tabular}

Source: Author's calculation on SPSS

\subsection{Reliability and Validity Analysis}

The internal and composite reliability of the scale was determined by calculating Cronbach's alpha and critical ratios (CR). The Cronbach's alpha values of all constructs were greater than 0.7. Similarly, the CR values were greater than 0.6 which indicated internal and composite reliability of the constructs.Validity of the measurement scales was determined by measuring AVE (Average variance extracted) values. The scales exhibited AVE values greater than 0.5 which was indication of validity of measurement scales. Moreover, two assistant professors of Management Science checked the content of the scales and approved it. The results of reliability and validity analyses are presented in Table 2 .

Table 2: Results of Reliability and Validity Analysis

\begin{tabular}{lccc}
\hline Construct & $\begin{array}{c}\text { Cronbach's } \\
\text { Alpha }\end{array}$ & CR & AVE \\
\hline Communication Strength & .889 & .954 & .742 \\
Perceived Supervisor Support & .882 & .896 & .654 \\
Organizational Trust & .857 & .883 & .813 \\
Employee's Engagement & .916 & .957 & .827 \\
\hline
\end{tabular}

Source: author's calculation in SPSS 


\subsection{Correlation Analysis}

Pearson Correlation was used to measure the strength of association among Communication Strength (CS), Perceived Supervisor Support (PSS), Organizational Trust (OT) and Employee Engagement (EE). All the variables had moderate positive and significant correlations as presented in Table 3.

Table 3: Results of Correlations Analysis ( $\mathrm{N}=\mathbf{2 4 4})$

\begin{tabular}{lllcc}
\hline Variables & CS & PSS & OT & EE \\
\hline CS & 1 & & & \\
PSS & $.395^{* *}$ & 1 & & \\
OT & $.299^{* *}$ & $.376^{* *}$ & 1 & 1 \\
EE & $.409^{* *}$ & $.345^{* *}$ & $.572^{* *}$ & \\
\hline
\end{tabular}

$* * \mathrm{p}<0.05, * \mathrm{p}<0.01$

\subsection{Testing of Hypotheses}

Simple linear regression was used to test the hypothesized relationships among OC, PSS, OT and EE. The conceptual framework given in Figure 1 shows the causal relationship among variables. The results of regression analysis are presented in Table 4.

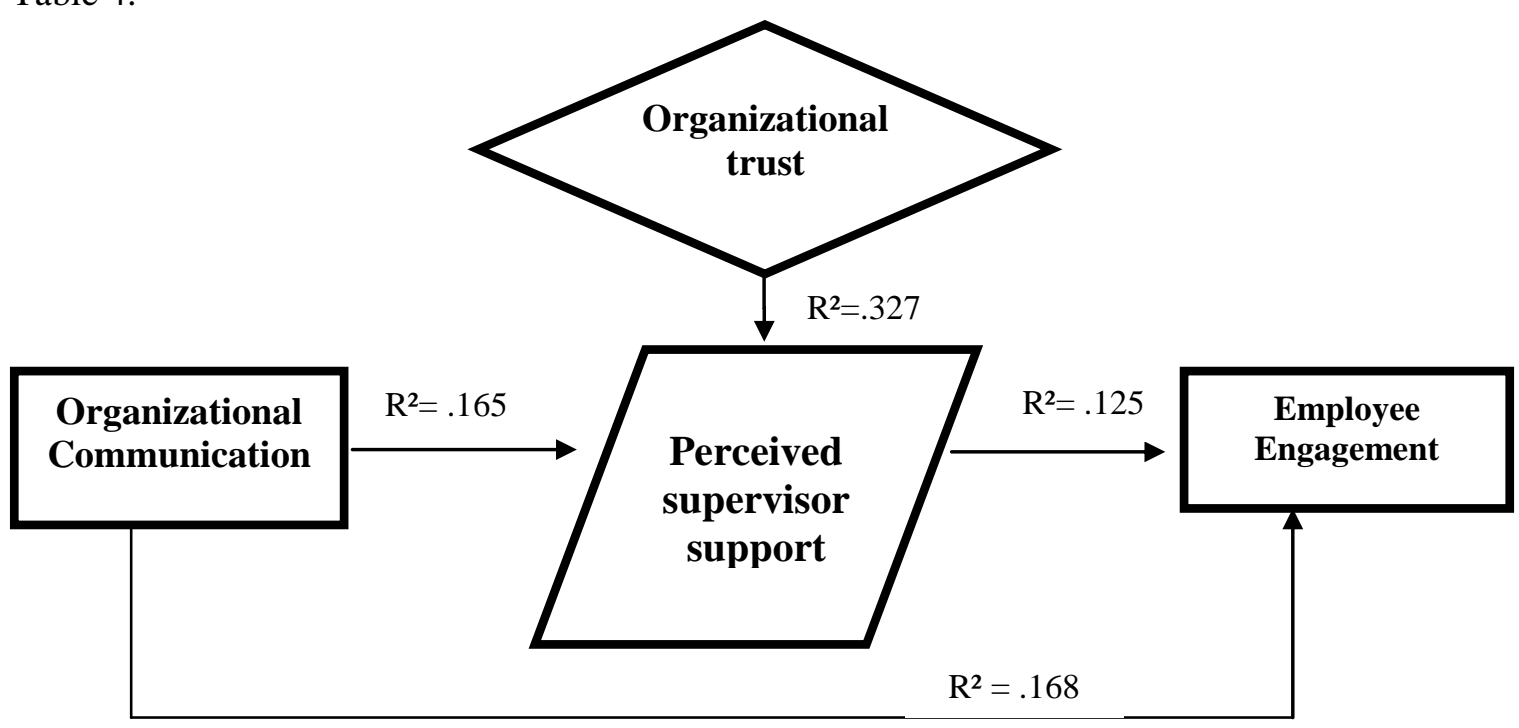

Figure. 1.Conceptual Framework

Table 4: Results of Regression Analyses Indicating the Causal Relationship between CS, EE and PSS.

\begin{tabular}{|c|c|c|c|c|c|c|c|}
\hline Hypothesis & $\mathbf{R}^{2}$ & $\overline{\mathbf{B}}$ & S.E & t-test & Sig & F-test & Sig. \\
\hline H1: CS (IV) $\mathrm{EE} \rightarrow(\mathrm{DV})$ & .168 & .466 & .639 & 7.12 & 0.00 & 50.73 & 0.00 \\
\hline$H 2: \mathrm{CS}(\mathrm{IV}) \mathrm{PSS} \rightarrow(\mathrm{DV})$ & .165 & .396 & .566 & 6.82 & 0.00 & 46.60 & 0.00 \\
\hline$H 3: \operatorname{PSS}(I V)$ EE $\rightarrow$ (DV) & .125 & .403 & .067 & 6.00 & 0.00 & 36.10 & 0.00 \\
\hline
\end{tabular}


Hypothesis 1: There is significantly positive impact of communication strength on employee engagement. The value of $\mathrm{R}$ square (.168) and $\mathrm{T}(7.12)$ confirms the hypothesis.

Hypothesis 2: There is significantly positive impact of communication strength on perceived supervisor support, proved by the value of $\mathrm{R}$ square (0.165) and $\mathrm{T}(6.82)$.

Hypothesis 3: Perceived supervisor support positively impact employee engagement. Hypothesis is accepted, R square (.125), T (6.00) with significant value of 0.00 .

\subsection{Mediation Analysis (Baron \& Kenny, 1986)}

In order to conduct mediation analysis Barron and Kenny (1986) method was followed. The mediating variable in the study isperceived supervisor support, so four separate tests have been performed, to check the mediation effect ofperceived supervisor support on employee engagement. Table 5 shows the summary results of the mediation of job satisfaction between organizational justice and employee's commitment.

Table 5: Barron and Kenny (1986) Method for Mediation Analysis (N=244)

\begin{tabular}{lllllll}
\hline & $\mathbf{R}$ & $\mathbf{R}^{2}$ & $\mathbf{F}$ & $\mathbf{B}$ & $\mathbf{T}$ & Sig \\
\hline Assumption 1:CS (IV) EE $\rightarrow$ (DV) & .409 & .168 & 50.73 & .466 & 7.12 & 0.00 \\
$\begin{array}{l}\text { Assumption2:CS(MV)PSS } \rightarrow(\mathbf{D V}) \\
\text { Assumption3:PSS(IV) EE } \rightarrow \text { M) }\end{array}$ & .395 & .156 & 46.61 & .396 & 6.82 & 0.00 \\
& .354 & .125 & 36.10 & .403 & 6.00 & 0.00 \\
$\begin{array}{l}\text { H6a: CS(IV) } \\
\left.\begin{array}{l}\text { EE (DV) } \\
\quad \text { PSS(MV) }\end{array}\right\}\end{array}$ & .409 & .168 & 50.73 & .466 & 7.12 & 0.00 \\
\hline & .460 & .211 & 33.64 & .259 & 3.70 & 0.00 \\
\hline
\end{tabular}

$* \mathrm{p}<0.05$

H6 (a): : perceived supervisor support mediates the relationship between organizational trust and employee engagement. *p<0.05

Step 1: communication strength positively impacts the employee's engagement level to their jobs. It is evident from the value of $\mathrm{R}$ which is 0.409 and $\mathrm{R}^{2}$ which is .168 . Model fitness value is 50.73 which show that the relation is strong to measure. The value of $\mathrm{T}$ is also greater than 2 which is 7.12 which confirms that Step is valid at 0.000 significance value.

Step 2: communication strength positively impacts perceived organizational support in an organization. Value of $\mathrm{R}$ is 0.394 and $\mathrm{R}^{2} .156$. The value of model fitness is also acceptable. The value of $\mathrm{T}(6.82)$ confirms the positive relation between the two variables.

Step 3: perceived organizational support positively impacts employee's engagement. Value of $\mathrm{R}$ is 0.354 and $\mathrm{R}^{2} 0.168$. The value of model fitness is also acceptable. The value of $\mathrm{T}$ (6.00) confirms the positive relation between the two variables.

Step 4: communication strength and perceived organizational support positively impacts employee's engagement level in an organization. Values of R were 0.409 and0.460, which shows mediation effect of the variables on employee's engagement. The value of model fitness is 133.21 which make it a strong relation to measure. The value of $\mathrm{T}$ (7.12) confirms the positive relation between the two variables and dependent variable. From the above results it can be safely said that perceived supervisor support partially mediate between communication strength and employee's engagement. 


\subsection{Moderation Analysis}

Organizational trust was the moderating variable in the research model. Following is the moderation analysis of the organizational trust on the communication strength and employee's engagement.

Table 6: Barron and Kenny (1986) Method for Moderation Analysis (N=244)

\begin{tabular}{lllllll}
\hline & R & $\mathbf{R}^{2}$ & F & B & T & Sig \\
\hline Assumption 1:PSS (IV) EE $\rightarrow$ DV) & .354 & .125 & 36.10 & .403 & 6.00 & 0.00 \\
Assumption 2:PSS(MV) OT $\rightarrow$ DV) & .376 & .141 & 41.49 & .985 & 6.44 & 0.00 \\
Assumption 3:OT(IV) EE $\rightarrow$ MV) & .572 & .327 & 122.32 & .587 & 11.06 & 0.00 \\
\hline
\end{tabular}

H7):.organizational trust moderates the relationship between perceived supervisor support and employee engagement. ${ }^{*} \mathrm{p}<0.05$

Step 1: Perceived supervisor support positively impacts the employee's engagement level to their jobs. It is evident from the value of $\mathrm{R}$ which was 0.354 and $\mathrm{R}^{2}$ which was 0.125 . Model fitness value was 36.10 which show that the relation was strong to measure. The value of $\mathrm{T}$ was also greater than 2 which is 6.00 which confirmed that Step 1 was valid at 0.05 significance value.

Step 2: Perceived supervisor support positively impacts organizational trust. Value of $\mathrm{R}$ is 0.376 and $\mathrm{R}^{2} \quad 0.141$. The value of model fitness was also strong and acceptable which was 41.49 . The value of $\mathrm{T}$ (6.44) confirms the positive relation between the two variables.

Step 3: Organizational trust positively impacts employee engagement. Value of $\mathrm{R}$ was 0.572 and $R^{2}$ 0.327. The value of model fitness was also acceptable. The value of $\mathrm{T}$ (11.06) confirmed the positive relation between the two variables.

Step 4: Organizational trust and perceived supervisor support positively impacts employee's engagement level in an organization. Value of $\mathrm{R}$ was 0.527 which shows moderation effect of the variables on employee's engagement. The value of model fitness was 122.28 which made it a strong relation to measure. The value of $\mathrm{T}$ (11.05) confirmed the positive relation between the two composite variables and dependent variable. From the above results it can be concluded that organizational trust moderates the relationship between perceived supervisor support and employee's engagement.

\section{Discussion}

The study tested the relationship of communication strength and employees engagement. Apart from these, perceived supervisor support was tested as a mediating variable and organizational trust a moderating variable between perceived supervisor support and employee's engagement. The results revealed that communication strength has positive impact on employee's engagement. Perceived supervisor support also mediated the relationship of communication strength and employee engagement. On the other hand, organizational trust moderated the relationship ofPerceived supervisor support and employee's engagement. There is a strong link between employee engagement and communication strength in an organization. Effective communication of goals and objectives to all employees and giving them attention to their feedback and concerns. This not only ensure strength in communication climate of organization but also establish trust. Communication strength is instrumental in creating trust in the eyes of employees for organizational policies. This tendency in turns increases the level of employee engagement.

Strong communication climate in organizations develop effective coordination and cooperation among its various departments. Individual communication among 
employees makes them more open and ideal and they give positive response to any call for the success of organization. Individual communication as well as effective communication structure establishes a solid link between employees and their supervisors and this affinity increases their trust on organization, as a result of which employee engagement increases. Therefore, organizational trust strengthen the relationship of employee's engagement and perceived supervisor support. The role of supervisor is vital in creating and sustaining the level of engagement among employees. For this they (supervisor) need to have a comprehensive plan for sustaining the level of job engagement in employees. Communication among employees and that of employees and managers should be strong enough, so that there should be free flow of new ideas, suggestions, as well concerns between the two tiers of the organization. This will not only increase the trust on managers on the part of employees but will also increase employee's engagement with their jobs as well as organization. Managers or supervisors have key role in engagement or disengagement of employee's with their jobs. Continuous communication between the two increases the trust between them. If communication climate is developed in an organization, employee's feel ease in exchanging views with managers regarding any matter. These tendencies foster an employee friendly work environment that is marked by mutual trust and zeal to go an extra mile for the organization.

\subsection{1 Conclusion}

In a nut shell, communication strength has positive impact on employee's engagement to their jobs. Perceived supervisor support also mediates the relationship between communication strength and employee's engagement. Organizational trust moderated the relationship of Perceived supervisor support and employee's engagement. Communication climate in an organization should be strong and free from any sort of barriers so that there is free flow of ideas and concerns from employees and managers and vice versa. Perception of supervisors also leads employees to have strong engagement with their jobs, for they found ease in performing any task assigned to them. Along with these, trust of employees on organization and management is the key behind high engagement to their jobs.

\subsection{2 Implications}

The findings might lead managers to establish organizational procedures and policies that are fair and just for all employees with a view to lessen the negative and emotional effects of low engagement level of employees to their jobs. Organization could minimize potential stressors by promoting a strong communication system that could bridge the gap between managers and employees. Managers can enhance communication climate in organization by applying consistent performance standards, giving adequate feedback, and responding to any feedback from employees. Although communication climate is important predictor of increased employees engagement and job satisfaction, perceived supervisor support also carry equal importance to be taken into account.

\subsection{Limitations}

There were some limitations related to this research. First organizational communication and perceived supervisor support are vast areas of study, and it is not possible to conduct research on these in such a short span of time. Along with this, organizational communication strength has been taken as a composite variable, for it was not easy to measure it fully with all their dimensions at hand. Secondly, limited resources made it hard to gather data from a large sample size. Thirdly, the responses 
were self-reported. It is logical to believe that situational factors on a given day and time can affect the responses of the employees.

\subsection{Future Research Directions}

In future studies, communication strength can be separately checked with employee's performance and managerial styles in an organization. Apart from this, different variables such as workplace deviance, work force diversity, organizational culture and employee's commitment can be taken as moderators to check its impact on employee's engagement. Similarly, there are various other variables which may be taken as either moderator or mediator like, compensation, organizational loyalty and employee's training. The current study has targeted only the Pakistan's banking sector companies. In future, this research can be conducted in service as well as manufacturing sectors of Pakistan.

\section{References}

Abbasi, A. S., \& Alvi, A. K. (2012). Impact of organizational justice on employee engagement in banking sector of Pakistan. Middle-East Journal of Scientific Research, 12(5), 643-649.

Abu Bakar, H., Dilbeck, K. E., \& McCroskey, J. C. (2010). Mediating role of supervisory communication practices on relations between leader-member exchange and perceived employee commitment to workgroup. Communication Monographs, 77(4), 637-656.

Abugre, J. B. (2013). Current and Desired Employee Communication Patterns in SubSaharan Africa: Empirical Evidence on Four Ghanaian Organizations.Journal of African Business, 14(1), 33-46.

Acosta, A, H., Salanova, S., M., \& Llorens Gumbau, S. (2012). How organizational practices predict team work engagement: The role of organizational trust.

Alfes, K., Shantz, A. D., Truss, C., \& Soane, E. C. (2013). The link between perceived human resource management practices, engagement and employee behaviour: a moderated mediation model. The international journal of human resource management, 24(2), 330-351.

Alfes, K., Truss, K., Soane, E., Rees, C., \& Gatenby, M. (2010). Creating an Engaged Workforce.CIPD Research Report, London: CIPD.

Avolio, B. J., Gardner, W. L., Walumbwa, F. O., Luthans, F., \& May, D. R. (2004). Unlocking the mask: A look at the process by which authentic leader's impact follower attitudes and behaviors. The leadership quarterly, 15(6), 801-823.

Bakker, A.B., \& Xanthopoulou, D. (2009). The Crossover of Daily Work Engagement: Test of an Actor-Partner Interdependence Model. Journal of Applied Psychology, 94(6) 1562-1571.

Balain, S., \& Sparrow, P. (2009). Engaged to Perform. CPHR White Paper 09/04, Lancaster

Baron, R. M., \& Kenny, D. A. (1986). The moderator-mediator variable distinction in social psychological research: Conceptual, strategic, and statistical considerations. Journal of personality and social psychology, 51(6), 1173.

Berger, B. (2008). Employee=organizational communications. Institute for Public Relations. Gainesville, FL: Institute for Public Relations. Retrieved from http://www.instituteforpr.org/topics/employee-organizational-communications/

Bhatnagar, J., \& Biswas, S. (2010). Predictors \& outcomes of employee engagement: Implications for the resource-based view perspective. Indian Journal of Industrial Relations, 273-286. 
Cummings, L. L., \& Bromiley, P. (1996). The organizational trust inventory (OTI). Trust in organizations: Frontiers of theory and research, 302(330), 39-52.

Decramer, A., Smolders, C., \& Vanderstraeten, A. (2013). Employee performance management culture and system features in higher education: relationship with employee performance management satisfaction. The International Journal of Human Resource Management, 24(2), 352-371.

Dvir, T., Eden, D., Avolio, B. J., \& Shamir, B. (2002). Impact of transformational leadership on follower development and performance: A field experiment. Academy of management journal, 45(4), 735-744.

Eisenberger, R., Huntington, R., Hutchison, S., \& Sowa, D. (1986). Perceived organizational support. Journal of Applied psychology, 71(3), 500.

Freeney, Y., \& Tiernan, J. (2006). Employee engagement: An overview of the literature on the proposed antithesis to burnout. The Irish Journal of Psychology, 27(3-4), 130-141.

Goh, S. K., \& Low, B. Z. J. (2013). The influence of servant leadership towards organizational commitment: The mediating role of trust in leaders. International Journal of Business and Management, 9(1), p17.

Hammer, L.B., Kossek, E.E., Zimmerman, K., \& Daniels, R. (2007), 'Clarifying the Construct of Family-Supportive Supervisory Behaviors (FSSB): A Multilevel Perspective,' in Exploring the Work and Non-work Interface (Vol. 6), eds. P. Perrewe and D. Ganster, Amsterdam: Elsevier, 165-204.

Hassan, M., Akram, A., \& Naz, S. (2012). The relationship between person organization fit, person-job-fit and turnover intention in banking sector of Pakistan: The mediating role of psychological climate. International Journal of Human Resource Studies, 2(3), Pages-172.

Bakar, H.A. \& Mustafa, C. S. (2013). Organizational communication in Malaysia organizations. Corporate Communications: An International Journal, 18(1), 87 - 109 Hunjra, A. I., Ali, M. A., Chani, M. I., Khan, H., \& Rehman, K. U. (2010). Employee voice and intent to leave: An empirical evidence of Pakistani banking sector. African journal of Business management, 4(14), 3056-3061.

Johnson, C. E., Shelton, P. M., \& Yates, L. (2012). Nice guys (and gals) finish first: Ethical leadership and organizational trust, satisfaction and effectiveness.International Leadership Journal, 4(1), 3-19.

Kahn, W. A. (1990). Psychological conditions of personal engagement and disengagement at work. Academy of management journal, 33(4), 692-724.

Liu, N. T., \& Ding, C. G. (2012). General ethical judgments, perceived organizational support, interactional justice, and workplace deviance. The International Journal of Human Resource Management, 23(13), 2712-2735.

Macey, W. H., \& Schneider, B. (2008). The meaning of employee engagement. Industrial and Organizational Psychology: Perspectives on Science and Practice, 1(1), 3-30. doi:10.1111/j.1754-9434.2007.0002.x mask: A look at the process by which authentic leader's impact follower attitudes and behaviors.

Maslach, C., \& Leiter, M. P. (1997). The truth about burnout.

May, D.R., Gilson, R.L., and Harter, L.M. (2004). The Psychological Conditions of Meaningfulness, Safety and Availability and the Engagement of the Human Spirit at Work.Research, 63, 1349-1355.

Mayer, R. C., Davis, J. H., \& Schoorman, F. D. (1995). An integrative model of organizational trust. Academy of Management Review. 20, 709-734. 
McCarthy, A., Cleveland, J. N., Hunter, S., Darcy, C., \& Grady, G. (2013). Employee work-life balance outcomes in Ireland: a multilevel investigation of supervisory support and perceived organizational support. The International Journal of Human Resource Management, 24(6), 1257-1276.

Mills, M. J., Matthews, R. A., Henning, J. B., \& Woo, V. A. (2014). Familysupportive organizations and supervisors: how do they influence employee outcomes and for whom? The International Journal of Human Resource Management, 25(12), 1763-1785.

Mohamed, M. S., Kader, M. M. A., \& Anisa, H. (2012). Relationship among Organizational Commitment, Trust and Job Satisfaction: An Empirical Study in Banking Industry. Research Journal of Management Sciences, ISSN, 2319, 1171.

Moye, M. J., \& Henkin, A. B. (2006). Exploring associations between employee empowerment and interpersonal trust in managers. Journal of Management Development, 25(2), 101-117.

Neves, P., \& Eisenberger, R. (2012). Management communication and employee performance: The contribution of perceived organizational support. Human Performance, 25(5), 452-464.

Nohria, N., Groysberg, B., and Lee, L.-E. (2008). Employee Motivation: A Powerful New Model. Harvard Business Review, 86(7-8), 78-84.

Payne, H. J. (2014). Examining the Relationship between Trust in SupervisorEmployee Relationships and Workplace Dissent Expression. Communication Research Reports, 31(2), 131-140.

Penger, S., \& Černe, M. (2014). Authentic leadership, employees' job satisfaction, and work engagement: a hierarchical linear modelling approach.Economic ResearchEkonomska Istraživanja, 27(1), 508-526.

Rajablou, Z., Sepasi, H., \& Nourbakhsh, P. (2014). Relationship between Organizational Justice, Trust and Workplace Spirituality. Advances in Environmental Biology, 8(17), 842-847.

Rees, C., Alfes, K., \& Gatenby, M. (2013). Employee voice and engagement: connections and consequences. The International Journal of Human Resource Management, 24(14), 2780-2798.

Rousseau, D. M., Sitkin, S. B., Burt, R. S., \&Camerer, C. (1998).Not so different afterall: A cross-discipline view of trust.Academy of Management Review, 23,393404.

Rurkkhum, S., \& Bartlett, K. R. (2012). The relationship between employee engagement and organizational citizenship behaviour in Thailand. Human Resource Development International, 15(2), 157-174.

Saks, A. M. (2011). Workplace spirituality and employee engagement. Journal of management, spirituality \& religion, 8(4), 317-340.

Schaufeli, W. B., Bakker, A. B., \& Salanova, M. (2006). The measurement of work engagement with a short questionnaire: A cross-national study. Educational and psychological measurement, 66(4), 701-716.

Schaufeli, W.B., Salanova, M., Gonzalez-Romá, V., \& Bakker, A.B. (2002). The measurement of engagement and burnout: A two sample confirmatory factor analytic approach. Journal of Happiness Studies, 3, 71-92.

Shamir, B., House, R. J., \& Arthur, M. B. (1993). The motivational effects of charismatic leadership: A self-concept based theory. Organization Science, 4(4), 577594. doi:10.1287/orsc.4.4.577 
Sharkie, R. (2009). Trust in leadership is vital for employee performance. Management Research News, 32(5), 491-498.

Sibiya, M., Buitendach, J. H., Kanengoni, H., \& Bobat, S. (2014). The prediction of turnover intention by means of employee engagement and demographic variables in a telecommunications organization. Journal of Psychology in Africa, 24(2), 131-143.

Snell, R. S., Yi, Z., \& Chak, A. M. (2013). Representational predicaments for employees: their impact on perceptions of supervisors' individualized consideration and on employee job satisfaction. The International Journal of Human Resource Management, 24(8), 1646-1670.

Top, M., Akdere, M., \& Tarcan, M. (2014). Examining transformational leadership, job satisfaction, organizational commitment and organizational trust in Turkish hospitals: public servants versus private sector employees. The International Journal of Human Resource Management, 1-24.

Torrente, P., Salanova, M., Llorens, S., \& Schaufeli, W. B. (2012). Teams make it work: How team work engagement mediates between social resources and performance in teams. Psicothema, 24(1), 106-112.

Townsend, K., Wilkinson, A., \& Burgess, J. (2014). Routes to partial success: Collaborative employment relations and employee engagement. The International Journal of Human Resource Management, 25(6), 915-930.

Wang, Z. (2014). Perceived supervisor support and organizational citizenship behavior: The role of organizational commitment. International Journal of Business and Social Science, 5(1).

Wollard, K. K., \& Shuck, B. (2011). Antecedents to employee engagement: A structured review of the literature. Advances in Developing Human Resources, 13(4), $429-446$. 